\section{Grateful DREADDs: Engineered Receptors Reveal How Neural Circuits Regulate Behavior}

Several novel strategies using engineered receptors activated by synthetic ligands or by light have recently ushered in a new era of brain research that allows for precise experimental manipulation of neuronal activity. These techniques are now being used to probe the involvement of discrete brain circuits in complex behaviors.

One such approach uses designer receptors exclusively activated by designer drugs (DREADDs) to modulate cellular functions (Rogan and Roth, 2011). This family of evolved muscarinic receptors has been shown to increase ( $\mathrm{G}_{\mathrm{s}}$-DREADD; $\mathrm{G}_{\mathrm{q}}$-DREADD) or decrease $\left(G_{i / o}\right.$-DREADD) cellular activity following administration of an otherwise inert synthetic ligand, clozapine- $n$-oxide (Armbruster et al, 2007). When packaged into viral vectors or expressed in transgenic mouse models, these tools allow cellular activity to be controlled in a defined spatial and temporal manner. For example, activation of hippocampal neurons by $\mathrm{G}_{\mathrm{q}}$-DREADD receptors amplifies $\gamma$-rhythms and increases locomotor activity and stereotypy in mice (Alexander et al, 2009). Activity of non-neuronal cells can also be controlled by DREADD receptors, as expression and activation of either $\mathrm{G}_{\mathrm{s}}$-DREADD or $\mathrm{G}_{\mathrm{q}}$-DREADD receptors in pancreatic $\beta$-cells increases insulin release, and repeated activation of these receptors leads to $\beta$-cell hypertrophy (Guettier et al, 2009).

We have been using DREADD receptor technology in a cell-specific manner to unravel the role of striatal circuits in neuropsychiatric disorders, such as drug addiction and obsessive-compulsive disorder. We developed viral vectors that use neuropeptide promoters
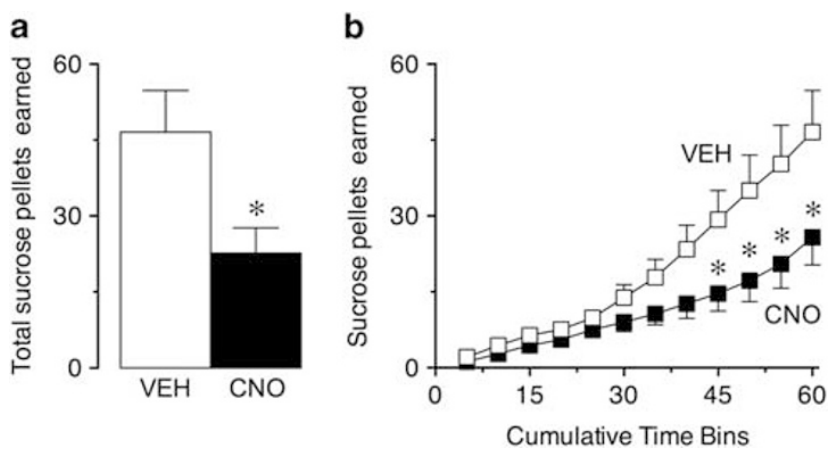

Figure 1. Transiently reducing excitability of striatonigral neurons impairs action-outcome learning of a simple operant task. (a) Activation of $\mathrm{G}_{\mathrm{i} / \mathrm{o}}$-designer receptors exclusively activated by designer drug (DREADD) receptors in striatonigral neurons in the dorsal striatum by clozapine- $n$-oxide (CNO) significantly decreased the total number of sucrose pellets that rats earned during a 1-h operant test session, compared with vehicle (VEH)-treated rats. $t$-test, $T_{17}=2.65,{ }^{\star} P=0.02$ (b) Significant differences in the number of sucrose pellets earned between groups were seen in the last quarter of the session (45-60 min time points), suggesting an impairment in learning acquisition in the CNOtreated rats. Two-way repeated measures analysis of variance (ANOVA), main effect of time: $F_{1,17}=41.74, P<0.0001$; main effect of pretreatment: $F_{1,17}=6,98, P=0.017$; interaction between time and pretreatment factors: $F_{1,17}=6.57, P<0.0001 ;{ }^{\star} P<0.05$, Bonferroni's post-hoc test. Data represent mean SEM. $N=7-12 /$ group.

(dynorphin or enkephalin) to target DREADD receptor expression to specific cell populations in the striatum (striatonigral versus striatopallidal neurons, respectively). We found that transiently decreasing activity of striatopallidal neurons in rats during repeated amphetamine exposure facilitated the development of behavioral sensitization, whereas disrupting activity of striatonigral neurons impaired the persistence of this phenomenon (Ferguson et al, 2011). Thus, these findings clearly demonstrate that striatonigral and striatopallidal neurons have critical, yet opposing, roles in the regulation of drug experience-dependent behavioral plasticity.

More recently, we have examined the role of striatonigral neurons in a simple operant learning task. We found that transiently inhibiting activity of these neurons in the dorsal striatum of rats interfered with the acquisition of lever pressing for a sugar reward (see Figure 1), indicating that activation of the striatonigral pathway is required for action-outcome learning. This data suggests that dysregulation of striatal circuits may therefore contribute to the development of the aberrant reward and reinforcement learning that is common to many neuropsychiatric disorders.

Increasingly selective pharmacological ligands have not necessarily improved the efficacy of drug treatments for neuropsychiatric disorders. Although safe and effective viral vectors for delivery of engineered receptors into humans still need to be refined, these tools may provide a distinct alternative to the currently available brain stimulation methods that are being used in the treatment of neuropsychiatric disorders. Thus, in addition to allowing us to parse the contribution of specific neural circuits in behaviors, perhaps engineered receptors may one day also offer the opportunity to provide therapeutic value without the 'dread'-ed side effects.

\footnotetext{
Susan M Ferguson ${ }^{1,2}$ and John F Neumaier ${ }^{1}$

${ }^{1}$ Department of Psychiatry and Behavioral Sciences, University of Washington, Seattle, WA, USA; ${ }^{2}$ Center for Integrative Brain Research, Seattle Children's Research Institute, Seattle, WA, USA

E-mail: neumaier@uw.edu
}

\section{DISCLOSURE}

The authors declare no conflict of interest. 
Alexander GM, Rogan SC, Abbas Al, Armbruster BN Pei Y, Allen JA et al (2009). Remote control of neuronal activity in transgenic mice expressing evolved G protein-coupled receptors. Neuron 63 27-39.

Armbruster BN, Li X, Pausch MH, Herlitze S, Roth BL (2007). Evolving the lock to fit the key to create a family of $G$ protein-coupled receptors potently activated by an inert ligand. Proc Natl Acad Sci USA 104: 5163-5168.

Ferguson SM, Eskenazi D, Ishikawa M, Wanat MJ, Phillips PE, Dong Y et al (2011). Transient neuronal inhibition reveals opposing roles of indirect and direct pathways in sensitization. Nat Neurosci 14 22-24.

Guettier JM, Gautam D, Scarselli M, Ruiz de Azua I, L $\mathrm{JH}$, Rosemond E et al (2009). A chemical-genetic approach to study $\mathrm{G}$ protein regulation of beta cel function in vivo. Proc Natl Acad Sci USA 106 19197-19202.

Rogan SC, Roth BL (2011). Remote control of neuronal signaling. Pharmacol Rev 63: 291-315.

Neuropsychopharmacology Reviews (2012) 37 296-297; doi: I0.1038/npp.20। I. 179

\section{Dopamine $\mathrm{D}_{3}$ Receptor Function and Cocaine Exposure}

Dopamine $\mathrm{D}_{3}$ receptors have been implicated as potential pharmacotherapeutic targets for cocaine addiction because of their restricted localization to limbic brain regions and involvement in the behavioral effects of cocaine (Heidbreder and Newman, 2010). The rationale for developing $\mathrm{D}_{3}$ receptor-selective treatment candidates has been strengthened by evidence suggesting a history of cocaine use dynamically impacts $D_{3}$ receptor expression and activity.

The recent development of highaffinity $\mathrm{D}_{3}$ receptor-selective compounds and the validation of agonistelicited yawning as a $\mathrm{D}_{3}$-specific unconditioned behavior (Collins et al, 2007) have provided an experimental framework for the examination of the relationship between cocaine exposure and $\mathrm{D}_{3}$ receptor function. One strategy for drug development is the use of partial agonists - compounds with less functional activity than full agonists in vitro. However, a limitation of this approach has been an inability to identify agonist actions of partial agonists in vivo. We recently reported that the partial agonist CJB090 and $\mathrm{D}_{3}$ receptor-selective compound PG619 elicited yawns similar to that of the $\mathrm{D}_{3}$ agonist quinpirole in monkeys with an extensive history of cocaine self-administration, while displaying no agonist-like activity in drug-naïve controls (Blaylock et al, 2011). This finding suggests that $D_{3}$ receptors may be functionally sensitized in response to chronic cocaine, thus differentially affecting the in vivo profile of low-efficacy $\mathrm{D}_{3}$ compounds. Although CJB090 and PG619 appeared to function as full agonists when measuring an unconditioned behavior (yawning), neither drug elicited reinstatement of cocaine seeking in these same monkeys, whereas quinpirole did. These findings suggest that $\mathrm{D}_{3}$ receptors contribute differentially to the multitude of behavioral effects associated with cocaine use.

Several key findings have suggested that cocaine-induced alterations to $\mathrm{D}_{3}$ receptors may persist and become more pronounced even after withdrawal from cocaine exposure. Using the behavioral sensitization paradigm, Collins et al (2011) reported progressive enhancements in agonist-elicited yawning in rats exposed to non-contingent cocaine injections for a 7-day period. These increases continued over the 42-day study and were associated with higher $\mathrm{D}_{3}$ receptor binding as determined with in vitro receptor autoradiography. Interestingly, exposure to cocaine in utero has also been shown to influence $\mathrm{D}_{3}$ receptor activity well into adulthood, as monkeys gestationally exposed to large amounts of cocaine displayed greater responses to quinpirole-elicited yawning than control monkeys up to 13 years after their prenatal cocaine exposure (Hamilton et al, 2010). Collectively, these findings suggest that cocaine exposure has long-lasting impacts on $\mathrm{D}_{3}$ receptor activity and expression.

As it relates to cocaine self-administration, we recently began studies using a food-drug choice self-administration paradigm and found that PG619 treatment reduced cocaine self-administration, which was en- hanced with continued PG619 administration. Although there have not been clinical trials reported with partial $\mathrm{D}_{3}$ receptor agonists, $\mathrm{D}_{3}$ receptor antagonists are currently being examined in phase I and II clinical trials for treatment of addictionrelated disorders, including tobacco dependence and obesity (NIDA, 2000). The evidence described above strongly demonstrates a relationship between cocaine exposure and $\mathrm{D}_{3}$ receptor alterations, and encourage clinical investigation of $D_{3}$ partial agonists and antagonists for cocaine addiction treatments.

\section{ACKNOWLEDGEMENTS}

These studies were supported by the NIDA grant DA 12460.

\section{Brandi L Blaylock ${ }^{1}$ and Michael A Nader ${ }^{1,2}$ \\ ${ }^{1}$ Department of Physiology and Pharmacology, Wake Forest University School of Medicine, Winston-Salem, NC, USA; ²Department of Radiology, Wake Forest University School of Medicine, Winston- Salem, NC, USA \\ E-mail: mnader@wakehealth.edu}

\section{DISCLOSURE}

The authors declare no conflict of interest.

Blaylock BL, Gould RW, Banala A, Grundt P, Luedtke $\mathrm{RR}$, Newman $\mathrm{AH}$ et al (2011). Influence of cocaine history on the behavioral effects of dopamine $D_{3}$ receptor-selective compounds in monkeys. Neuropsychopharmacology 36: 1104-1113.

Collins GT, Newman AH, Grundt P, Rice KC, Husbands SM, Chauvignac C et al (2007). Yawning and hypothermia in rats: effects of dopamine $D_{3}$ and $D_{2}$ agonists and antagonists. Psychopharmacology 193: 159-170.

Collins GT, Truong YN, Levant B, Chen J, Wang S, Woods JH (2011). Behavioral sensitization to cocaine in rats: evidence for temporal differences in dopamine $D_{3}$ and $D_{2}$ receptor sensitivity. Psychopharmacology 215: 609-620.

Hamilton LR, Czoty PW, Gage HD, Nader MA (2010). Characterization of the dopamine receptor system in adult rhesus monkeys exposed to cocaine throughout gestation. Psychopharmacology 210: 481-488.

Heidbreder CA, Newman AH (2010). Current perspectives on selective dopamine $D_{3}$ receptor antagonists as pharmacotherapeutics for addictions and related disorders. Ann NY Acad Sci 1187: 4-34.

National Institute on Drug Abuse; Massachusetts General Hospital (2000). Effectiveness of GSK598809, a selective $D_{3}$ antagonist, added to cognitive behavioral therapy and nicotine replacement therapy for smoking cessation and prevention of very early relapse to smoking. In: CinicalTrials.gov (Internet). National Library of Medicine (US): Bethesda (MD). (cited 2011 Jul 17). 